JPE 10-1-12

\title{
Power Conditioning System for a Grid Connected PV Power Generation Using a Quasi-Z-Source Inverter
}

\author{
Jong-Hyoung Park*, Heung-Geun Kim ${ }^{\dagger}$, Eui-Cheol Nho**, and Tae-Won Chun ${ }^{* * *}$ \\ $\dagger *$ Dept. of Electrical Engineering, Kyungpook National University, Korea \\ ** Dept. of Electrical Engineering, Pukyong National University, Korea \\ *** Dept. of Electrical Engineering, University of Ulsan, Korea
}

\begin{abstract}
This paper presents a grid connected photo-voltaic system using a quasi-Z-source inverter (QZSI) for power stage reduction. The power stage can be reduced because of an additional shoot-through stage which is a characteristic of QZSI. Therefore, by utilizing a QZSI the system's efficiency can be increased. In this paper, for applying a QZSI to a PV system, control methods such as maximum power point tracking (MPPT), point of common coupling (PCC) current control and PWM are studied and verified through simulation and experiment. In order to explain the above controllers, the characteristics of a QZSI are first analyzed. Then the MPPT control technique with a modified P\&O method, the PCC current control for the regulation of the dc-link capacitor voltage and the PWM methods for the proposed system are explained. The feasibility of the proposed algorithm is verified through simulation and experiment with a $3 \mathrm{~kW}$ system.
\end{abstract}

Key Words: MPPT, P\&O method, Photo-voltaic system, Quasi-Z-source inverter, Shoot through stage

\section{INTRODUCTION}

The use of renewable-energy generating systems has recently increased dramatically due to the exhaustion of fossil fuels and their impact on the environment. The unregulated output power of renewable energy sources should be regulated through inverters to satisfy the conditions for connection to the grid. Generally, the power conditioning system (PCS) consists of two power stages.

The cascaded arrangement of PCS increases not only the complexity of the power circuit and controller but also the cost and space requirements. Moreover, the increased number of power switches results in lower efficiency. As a result, many papers have dealt with topologies for high efficiency converters [1] or the new MPPT control techniques [2] for improving efficiency.

A Z-source inverter (ZSI) has been proposed to overcome the disadvantages of the conventional scheme with a unique impedance network [3]. A ZSI can buck or boost the input voltage using the shoot-through state and the modulation index in a single stage. Since no dead time is needed, the output voltage is free from voltage distortion. Due to these

\footnotetext{
Manuscript received Aug. 17, 2009; revised Oct. 30, 2009

† Corresponding Author: kimhg@knu.ac.kr

Tel: +82-53-950-5605, Fax: +82-53-950-5508, Kyungpook National Univ.

* Dept. of electrical Eng., Kyungpook National University, Korea

** Dept. of electrical Eng., Pukyong National University, Korea

$* * *$ Dept. of electrical Eng., University of Ulsan, Korea
}

advantages, the ZSI has been applied to single stage conversion applications, such as PV systems [4], [5], fuel cell systems [6] and ac motor drive systems [7].

The quasi-Z-source inverter (QZSI) is similar to the ZSI presented above, but has several advantages including, in various combinations; lower component ratings, reduced source stress, reduced component count and simplified control strategies [8].

In this paper, the PCS for a PV system using a QZSI is presented. Also a new MPPT algorithm, a PCC current control and a PWM method for the proposed PCS are suggested. Finally, the feasibility of the proposed algorithm is verified through simulation and experimental results with a $3 \mathrm{~kW}$ prototype system.

\section{QUASI-Z-SOURCE INVERTER}

The operation of a QZSI can be broken down into two states; the active state and the shoot through state.

When the inverter is in the shoot-through state for an interval $T_{o}$ during a switching cycle $T$, the following voltage equations can be described from Fig. 1 as:

$$
V_{C_{1}}=v_{L_{1}}, \quad V_{C_{2}}+V_{\text {in }}=v_{L_{2}}, \quad v_{\text {out }}=0
$$

When the inverter is in the active state for the interval $T_{1}$, during the switching cycle $T$, the voltage equations are as follows:

$$
\begin{aligned}
& v_{L_{1}}=V_{C_{1}}-\hat{v}_{\text {out }}=-V_{C_{2}} \\
& v_{L_{2}}=V_{\text {in }}-V_{C_{1}}=V_{\text {in }}-\hat{v}_{\text {out }}+V_{C_{2}}, \hat{v}_{\text {out }}=V_{C_{1}}+V_{C_{2}}
\end{aligned}
$$




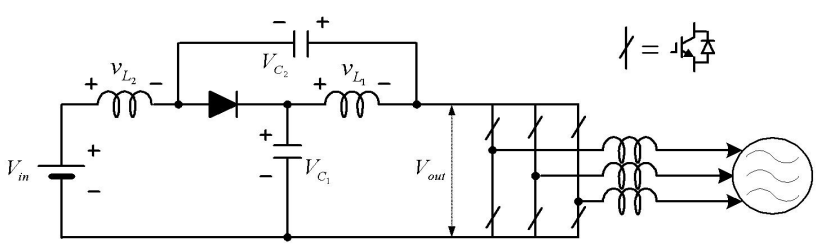

Fig. 1. Configuration of QZSI.

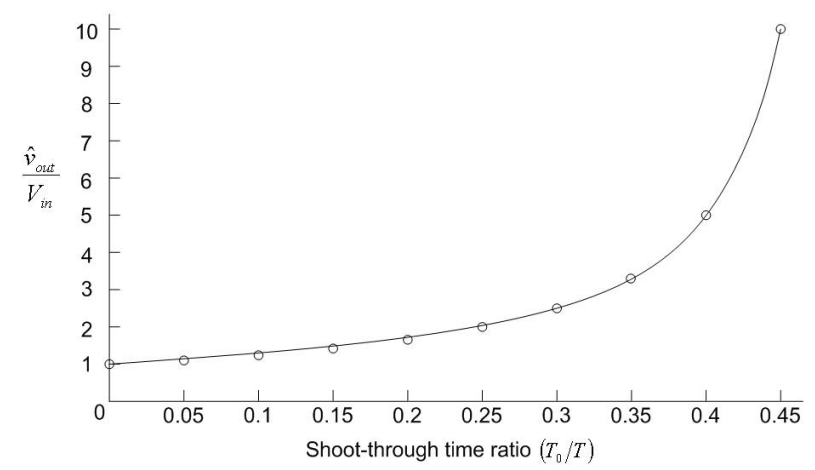

Fig. 2. Boosted voltages by shoot-through time.

During this period, the inverter is operated in the same manner as a standard voltage source inverter (VSI).

The average voltage of the inductor $v_{L_{1}}$, during one switching period $T$, should be zero in the steady state.

$$
\begin{aligned}
V_{L_{1}}=\bar{v}_{L_{1}} & =\frac{T_{0} \cdot V_{C_{1}}+T_{1} \cdot\left(-V_{C_{2}}\right)}{T} \\
& =\frac{T_{0} \cdot V_{C_{1}}+T_{1} \cdot\left(V_{C_{2}}-\hat{v}_{\text {out }}\right)}{T}=0 \\
T_{0} \cdot V_{C_{1}}= & T_{1} \cdot V_{C_{2}}, \quad V_{C_{1}}=\frac{T_{1}}{T} \cdot \hat{v}_{\text {out }}
\end{aligned}
$$

Also, the average voltage of the inductor, $v_{L_{2}}$ over one switching period $T$ should be zero in the steady state.

From (1), (2) and (3), we also have:

$V_{L_{2}}=\bar{v}_{L_{2}}=\frac{T_{0} \cdot\left(V_{C_{2}}+V_{i n}\right)+T_{1} \cdot\left(V_{i n}-V_{C_{1}}\right)}{T}$

$=\frac{T_{0} \cdot\left(V_{C_{2}}+V_{\text {in }}\right)+T_{1} \cdot\left(V_{\text {in }}-\hat{v}_{\text {out }}+V_{C_{2}}\right)}{T}=0$

$\hat{v}_{\text {out }}=\frac{T}{T_{1}-T_{0}} \cdot V_{\text {in }}, \quad V_{\text {in }}=V_{C_{1}}-V_{C_{2}}$

Similarly, the average dc-link voltage across the inverter bridge can be found as follows:

$$
\begin{aligned}
V_{\text {out }}=\bar{v}_{\text {out }} & =\frac{T_{0} \cdot 0+T_{1} \cdot\left(V_{C_{1}}-v_{L_{1}}\right)}{T} \\
& =\frac{T_{1} \cdot\left(V_{C_{1}}+V_{C_{2}}\right)}{T}=V_{C_{1}}
\end{aligned}
$$

And, from (3), (4) and (5), we have:

$$
V_{\text {out }}=V_{C_{1}}=\frac{T_{1}}{T_{1}-T_{0}} \cdot V_{\text {in }}
$$

Therefore the input voltage of a QZSI is well defined and can be boosted by using the shoot-through ratio. Fig. 2 shows the relationship between the QZSI output voltage and the shoot-through ratio.

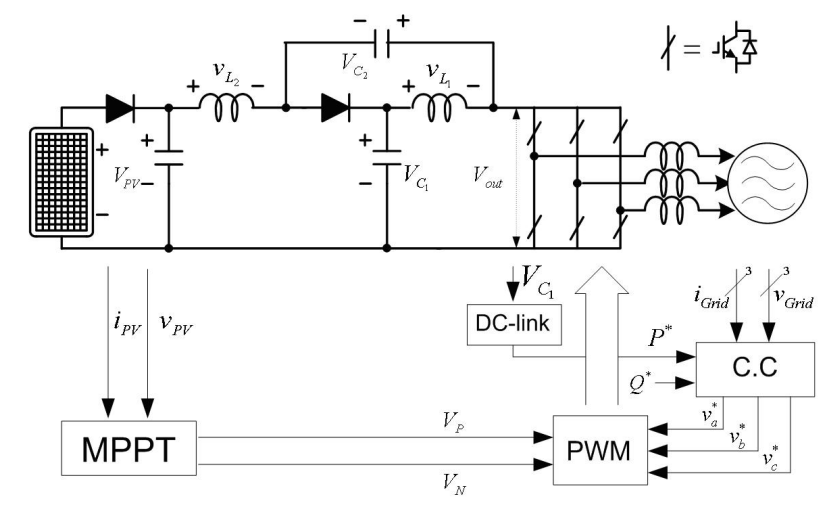

Fig. 3. Control block diagram of a PV-system using QZSI.

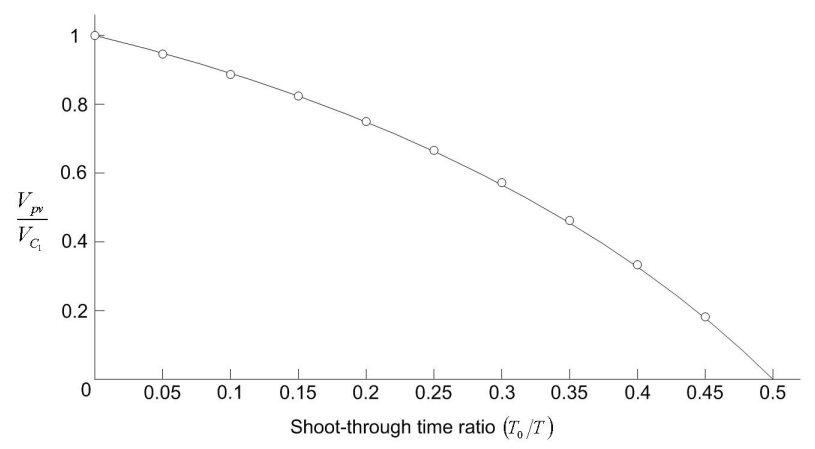

Fig. 4. Reduced input voltage of a PV-array by the shoot-through time of QZSI.

During the shoot-through state, in the case of a ZSI, the input current is zero due to a blocking diode. Because of this, the output current of the PV array should be continuous for the MPPT control or the life of the PV array. However in the case of a QZSI, the input current is continuous due to the source which is located on the inductor side.

The output voltage of a ZSI and a QZSI are zero during the shoot-through time interval. If the shoot-through time interval is in the switching state, the output voltage is affected. Thus the shoot-through time interval should be located within the zero state so that it will not affect the output voltage. This is mentioned below, in the section covering PWM signal generation.

Fig. 3 shows a grid connected PV system using a QZSI. In contrast with a traditional PV system, the PCS is a single power stage and the number of power switches is reduced. Generally, the inverter for a grid-connected PV system should satisfy two controls, such as MPPT control and PCC current control. Thus, the methods for these controls for the QZSI topology should be developed.

\section{CONTROL OF A GRID-CONNECTED PV SYSTEM}

\section{A. MPPT control}

If the capacitor voltage $V_{C_{1}}$ of an impedance network is controlled so that it is a constant value, the input voltage of a QZSI decreases as the shoot through time interval increases. This can be seen in equation (7) and in Fig. 4.

$$
V_{P V}=\frac{T_{1}-T_{0}}{T_{1}} \cdot V_{C_{1}}
$$




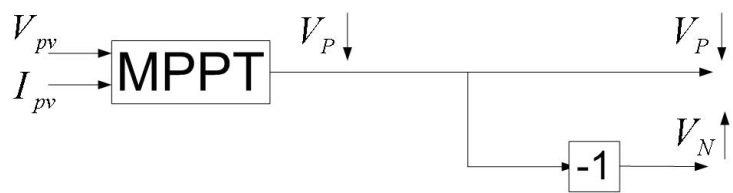

(a)

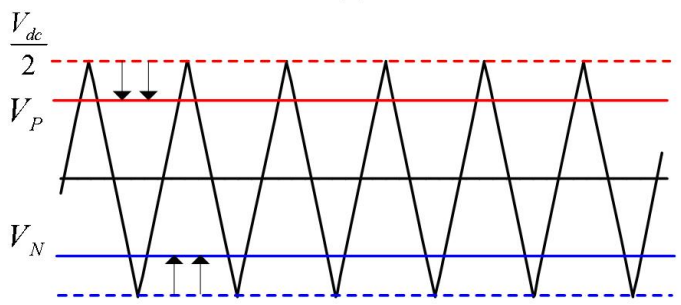

(b)

Fig. 5. MPPT control strategy: (a) Control block diagram, (b) simple boost method for shoot-through.

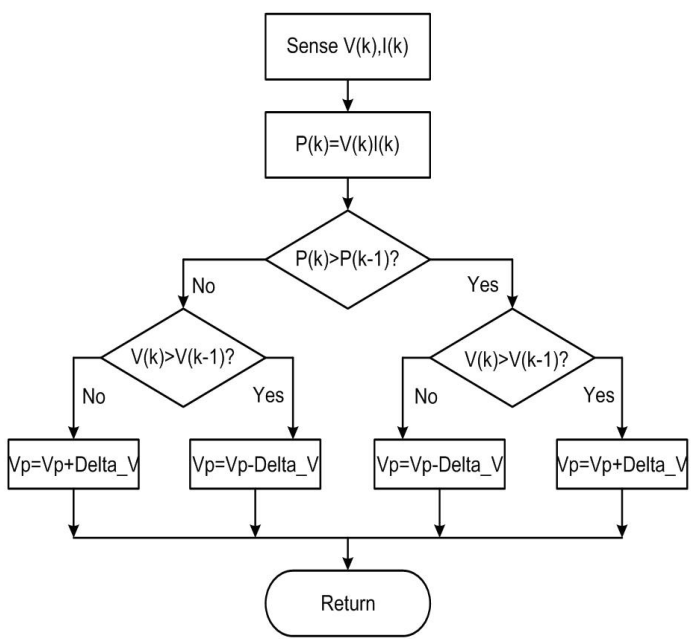

Fig. 6. Modified P\&O method for the shoot-through reference.

The input voltage of a QZSI is the output voltage of a PV array. As a result, the operating point of a PV-array can be controlled by adjusting the shoot-through time interval. Therefore, if the capacitor voltage is controlled at a constant value, MPPT control can be realized by the shoot-through time interval.

Fig. 5 shows the method for shoot-through reference generation for MPPT control. The voltage and current of a PVarray are used for MPPT control by the P\&O method. In the $\mathrm{P} \& \mathrm{O}$ method, the voltage reference becomes the shoot-through reference signal $V_{P}^{*}$.

If $V_{P}^{*}$ is lower than the carrier signal, then all the switches in the three legs will be in the on position. Also if $V_{N}^{*}$ is higher than the carrier signal, then all the switches will be in the on position. Therefore, the shoot through frequency is twice that of the carrier frequency. As a result, if the value of $V_{P}^{*}$ decreases below that of $V_{d c} / 2$, then the shootthrough time interval will be increased. As a result, the real voltage decreases as the shoot through time interval increases as mentioned in equation (7).

Fig. 6 shows the modified P\&O method for MPPT control of a PV system using a QZSI.

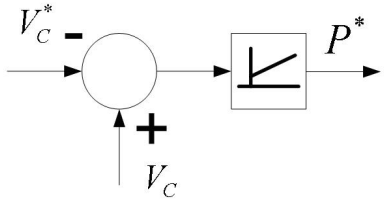

Fig. 7. Control block diagram for PCC current control.

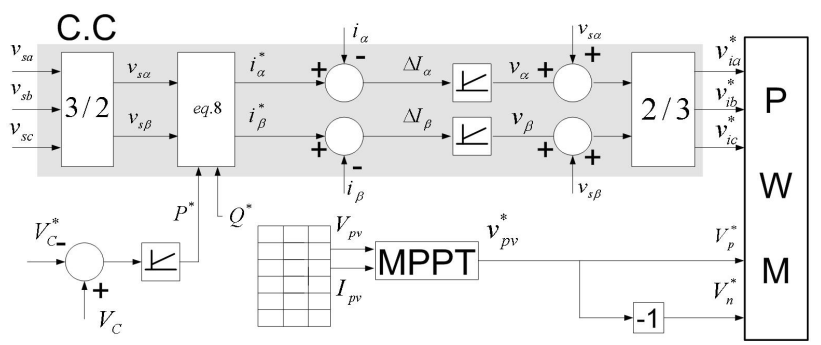

Fig. 8. Control strategy of PV-system using QZSI.

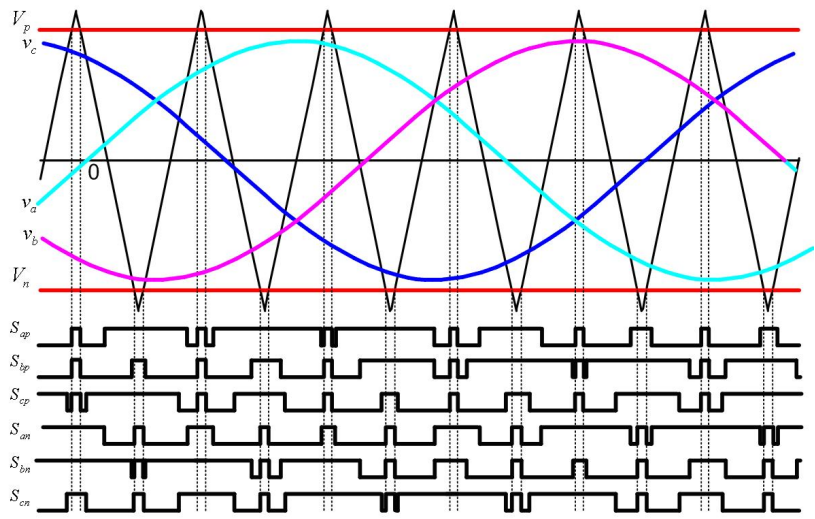

Fig. 9. PWM signal generating strategy.

\section{B. PCC current control}

In this paper, the PCC current is controlled by regulating the capacitor voltage $V_{C_{1}}$. Using this control, the generated power of a PV array is injected directly into the grid.

If the real voltage is higher than the reference voltage, the error is reflected as a positive active power reference, as seen in fig. 7. Then, by the relative equation (8) of a traditional inverter, the current reference is increased. As a result, the power can be injected directly into the grid as the generated power of a PV array.

If the reactive power reference $Q^{*}$ is zero, the output current is in phase by the PLL(phase locked loop). Also $K$ is the coefficient of DQ conversion.

$$
i_{\alpha}^{*}=K \cdot \frac{v_{\alpha} P^{*}+v_{\beta} Q^{*}}{\left(v_{\alpha}^{2}+v_{\beta}^{2}\right)}, \quad i_{\beta}^{*}=K \cdot \frac{v_{\beta} P^{*}+v_{\alpha} Q^{*}}{\left(v_{\alpha}^{2}+v_{\beta}^{2}\right)}
$$

A block diagram of these controls is shown in fig. 8 .

\section{PWM scheme for QZSI}

Fig. 9 showing that the control signal $V_{P}^{*}$ should have a limit value to guarantee traditional VSI action. Therefore the maximum value of $V_{P}^{*}$ is $V_{d c} / 2$ and the minimum value is the amplitude of the three phase reference voltage signals. 


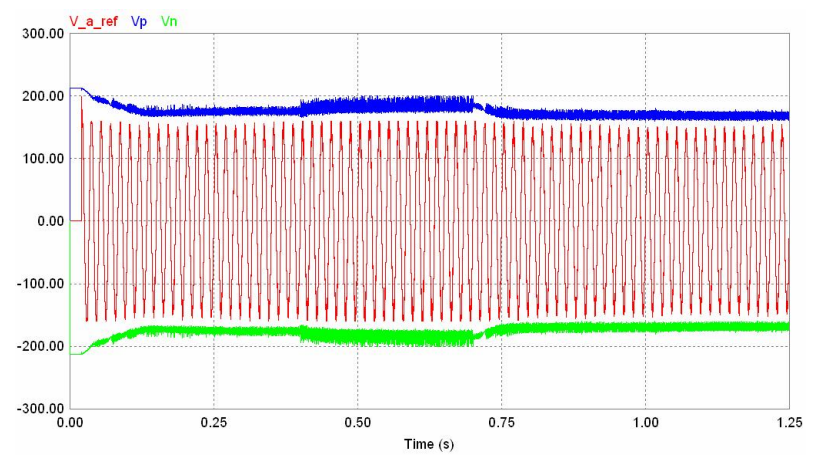

(a) References for the PWM signal generation

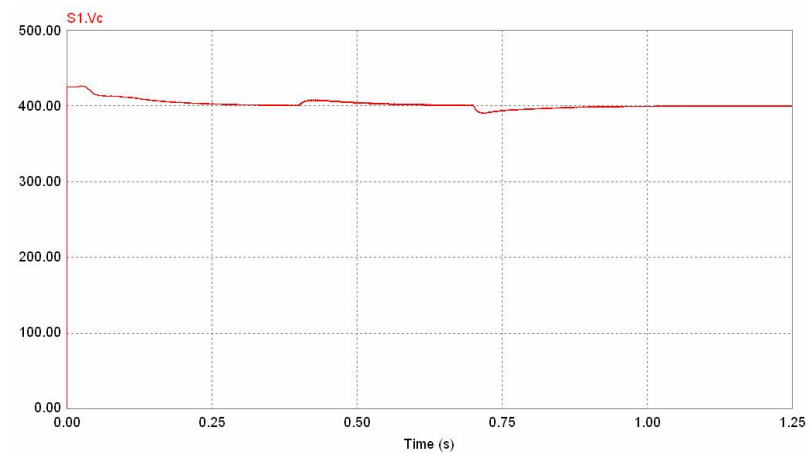

(c) Controlled voltage

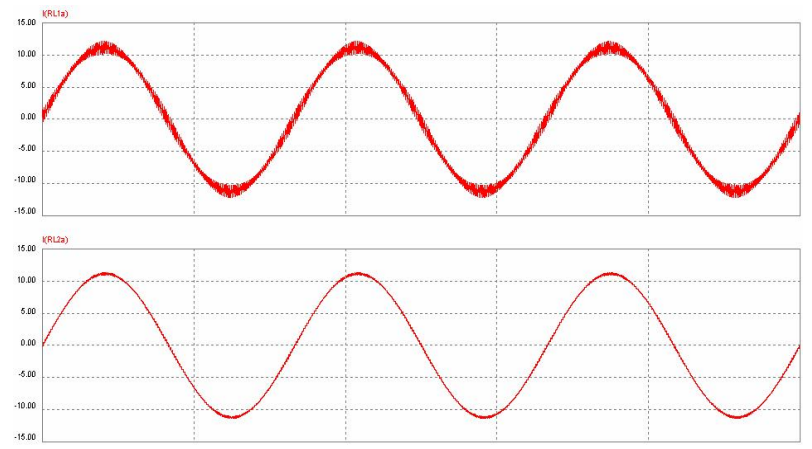

(e) The output current waveforms of inverter

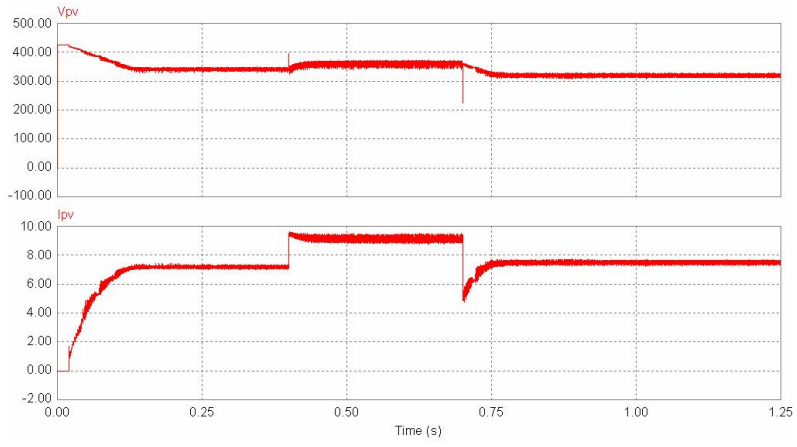

(b) Output waveforms of the PV array

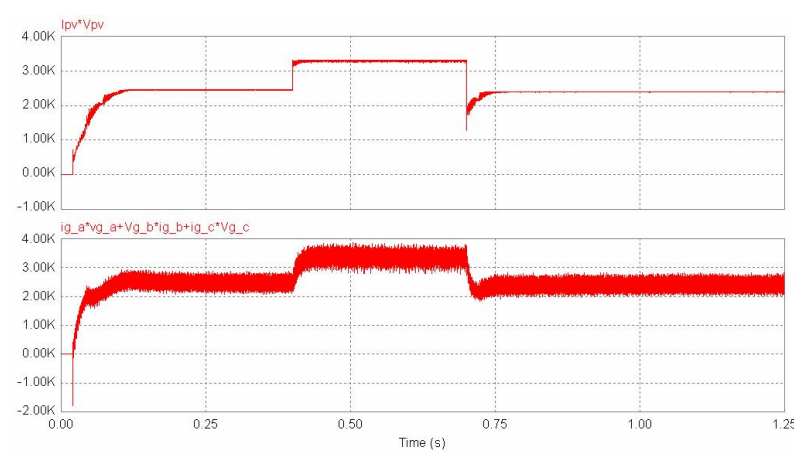

(d) Output power of the PV array and injected power of the QZSI
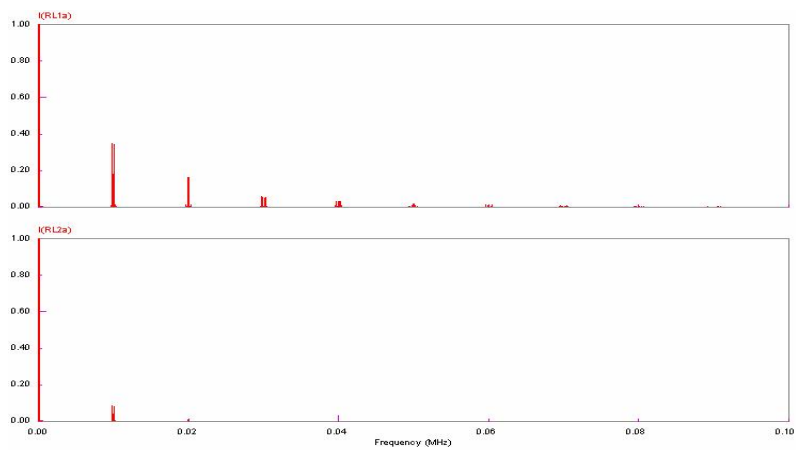

(f) The current THD results of the inverter

Fig. 10. Output waveforms of the simulation.

\section{Simulation AND EXPERIMENT}

The simulation of a $3 \mathrm{~kW}$ grid connected PV system using a QZSI is carried out through a PSIM. A simple boost method is used in this paper for the shoot-through. An LCL filter is used to improve the output current THD of the inverter [9]. The inductance of $\mathrm{L}$ at the inverter side is $2.5 \mathrm{mH}$, the capacitance of filter capacitor is $5 \mathrm{uF}$ and the inductance of $\mathrm{L}$ at the grid side is $260 \mathrm{uH}$. Table 1 shows the conditions of the simulation.

Fig. 10(a) shows the reference signals for the generation of the PWM signal. The $V_{P}^{*}$ varies in order to track the MPP. Therefore, the shoot-through time interval is determined by the PV array characteristics. In this figure the characteristics of the PV array are changed twice; at $0.4 \mathrm{~s}$ and at $0.7 \mathrm{~s}$.

Fig. 10(b) shows that the operating point of the PV array is tracking the MPP. In fig. 10(c), the capacitor voltage $V_{C_{1}}$ is controlled in order to be constant. Fig. 10(d) shows that the power of the PV array is injected directly into the grid as it
TABLE I

THE CONDITION FOR SIMULATION OF PCS USING THE QZSI

\begin{tabular}{|c|c|c|c|c|}
\hline & \multirow{3}{*}{$\begin{array}{c}\mathrm{I} \\
425[\mathrm{~V}] \\
\end{array}$} & \multirow{3}{*}{$\frac{\mathrm{II}}{426.4[\mathrm{~V}]}$} & \multirow{3}{*}{$\begin{array}{c}\text { III } \\
380[\mathrm{~V}]\end{array}$} \\
\hline & & & & \\
\hline \multirow{5}{*}{ PV array } & $V_{o c}$ & & & \\
\hline & $I_{s c}$ & $7.9[\mathrm{~A}]$ & $9.75[\mathrm{~A}]$ & $10[\mathrm{~A}]$ \\
\hline & $V_{M P P}$ & $355[\mathrm{~V}]$ & $370[\mathrm{~V}]$ & $300[\mathrm{~V}]$ \\
\hline & $I_{M P P}$ & $7.3[A]$ & $8.85[\mathrm{~A}]$ & $8[A]$ \\
\hline & $P_{M P P}$ & $2.6[\mathrm{~kW}]$ & $3.27[K W]$ & $2.4[\mathrm{~kW}]$ \\
\hline \multirow{3}{*}{ Impedance Network } & $L_{1,2}$ & \multicolumn{3}{|c|}{$1[\mathrm{mH}]$} \\
\hline & $C_{1,2}$ & \multicolumn{3}{|c|}{$1000[\mu \mathrm{F}]$} \\
\hline & $V_{c}^{*}$ & \multicolumn{3}{|c|}{$400[V]$} \\
\hline \multirow{3}{*}{ Grid } & $V_{L L}$ & \multicolumn{3}{|c|}{$220\left[V_{m s}\right]$} \\
\hline & $f$ & \multicolumn{3}{|c|}{$60[\mathrm{~Hz}]$} \\
\hline & Phase & \multicolumn{3}{|c|}{$3[\Phi]$} \\
\hline Switching frequency & $f_{S}$ & \multicolumn{3}{|c|}{$10[\mathrm{kHz}]$} \\
\hline
\end{tabular}

is generated. Fig. 10(e) shows the output voltage waveforms of the inverter. $i_{i}$ is the inverter side current and an $i_{g}$ is the 


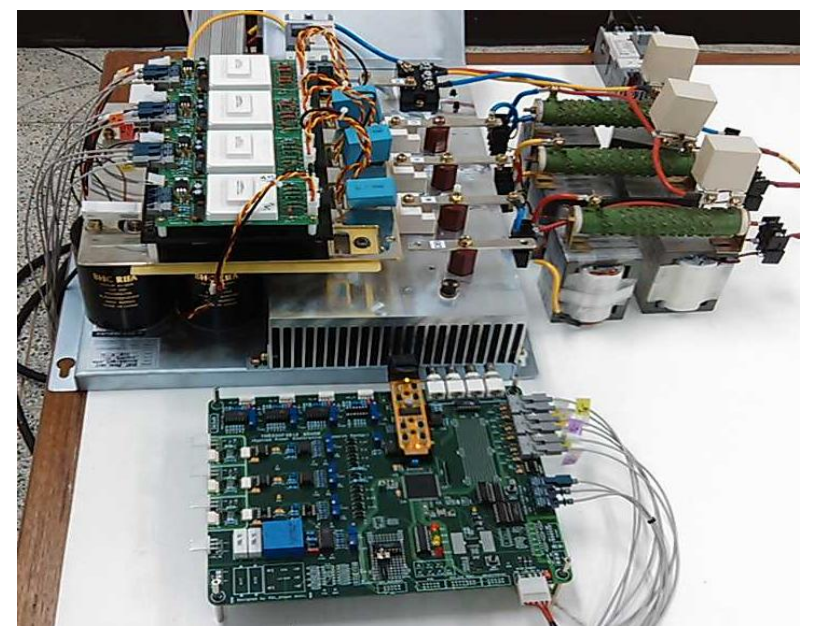

Fig. 11. Hardware for QZSI experiment

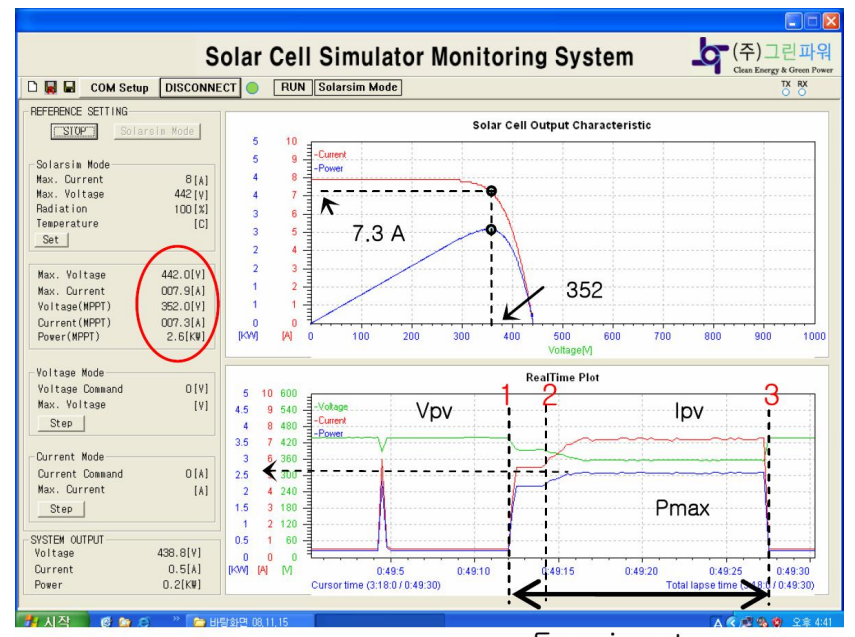

Experiment

Fig. 12. Experiment result of using the PV simulator.

grid side current. Fig. 10(f) is the current THD results from fig. 10(e). These figures show that the output current THD of the inverter is improved.

The experiment conditions are the same as the simulation conditions. The switching frequency is $10 \mathrm{kHz}$ and the grid line to line voltage is 220 Vrms.

Fig. 11 shows the hardware for the experiment. This consists of a single power stage (left of top), a LCL filter (right of top) and a controller (bottom).

Fig. 12 shows the PV array characteristic of a simulator and the result of the experiment. At first, the system is on at the PV array open circuit condition. At " 1 ," the switching starts without the shoot-through to enable the buildup of the capacitor voltage $V_{C_{1}}$ to the control level. The shoot-through for the MPPT control starts at "2". It is well described that the voltage, current and power of the PV array are controlled to track the MPP of the PV array.

Fig. 13 shows the results of the LCL filter experiment of the $3 \mathrm{~kW}$ system. This figure uses the same notation as the simulation. Therefore $i_{i}$ is the inverter side current and $i_{g}$ is the grid side current. The THD of the output current is improved.

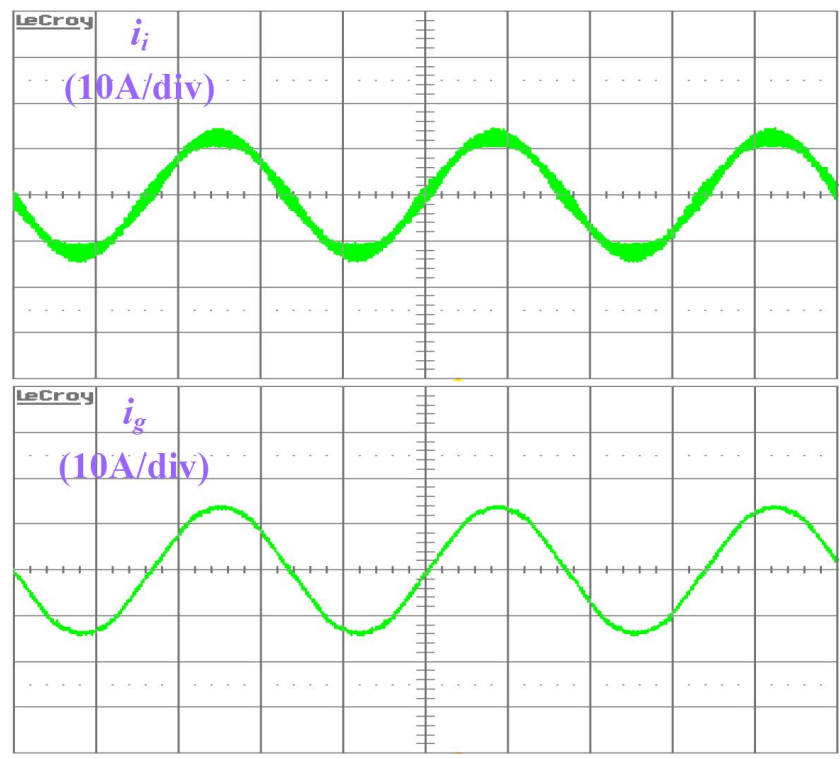

(a) The output current waveforms of inverter

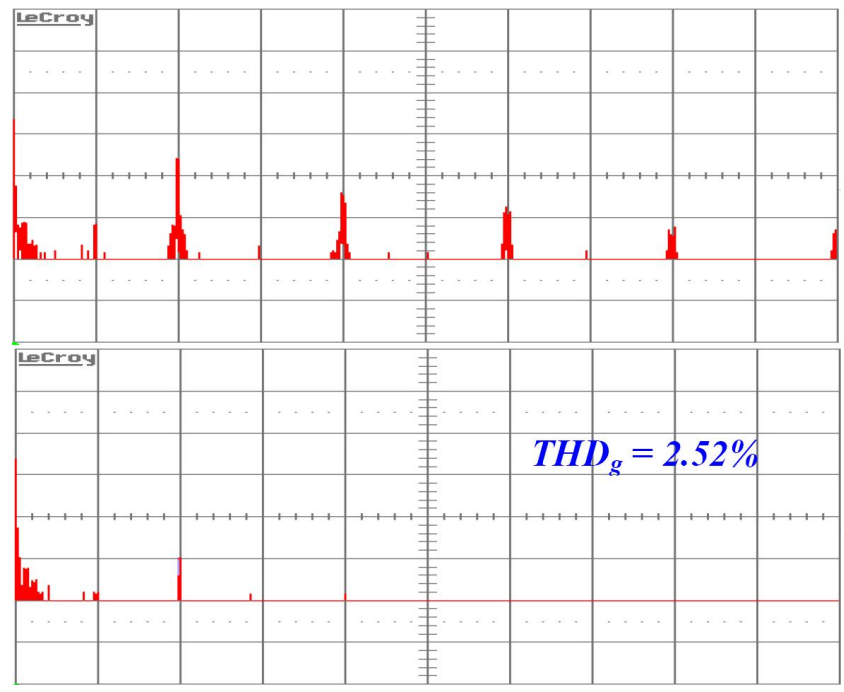

(b) The current THD results of the inverter

Fig. 13. Results of the LCL filter experiment of the $3 \mathrm{~kW}$.

\section{CONCLusions}

A power conversion circuit for a grid-connected PV system using a QZSI was suggested and analyzed in this paper. Because the PCS consists of a single stage with a QZS inverter, the power circuit and the controller are simple and can achieve a higher efficiency. Also, less space and cost are needed. A modified P\&O method is used for MPPT control. The output of the MPPT controller is the reference signal for generating a shoot through state. With this method, the operating point can be easily tracked to a maximum power point. Since no dead time is needed, the output voltage waveform is free from low frequency distortion. Finally, the feasibility is successfully verified through a simulation using a PSIM and an experiment.

\section{ACKNOWLEDGMENT}

This work is the outcome of a Manpower Development Program for Energy \& Resources supported by the Ministry of Knowledge and Economy (MKE). 


\section{REFERENCES}

[1] Byung-Duk Min, Jong-Pil Lee, Jong-Hyun Kim, Tae-Jin Kim, DongWook Yoo,Kang-Ryoul Ryu, Jeong-Joong Kim, and Eui-Ho Song; "A Novel Grid-Connected PV PCS with New High Efficiency Converter," Journal of Power Electronics, Vol. 8, No. 4, 2008. 10, pp. $309 \sim 316$.

[2] Ahmed G. Abo-Khalil, Dong-Choon Lee, Jong-Woo Choi, and HeungGeun Kim; "Maximum Power Point Tracking Controller Connecting PV System to Grid," Journal of Power Electronics, Vol. 6, No. 3, 2006. 7 , pp. $226 \sim 234$.

[3] Fang Zheng Peng; "Z-source inverter," IEEE Trans. on Industry Applications, Vol. 39, No. 2, March-April 2003, pp.504 - 510.

[4] Po Xu, Xing Zhang, Chong-wei Zhang, Ren-xian Cao, and Liuchen Chang, "Study of Z-Source Inverter for Grid-Connected PV Systems," Power Electronics Specialists Conference, 2006. PESC '06. 37th IEEE, June 2006, Page(s):1-5.

[5] Badin, R., Yi Huang, F. Z. Peng, and Heung-Geun Kim, "Grid Interconnected Z-Source PV System," Power Electronics Specialists Conference, 2007. PESC 2007. IEEE 17-21, June, 2007, Page(s):2328 - 2333.

[6] K. Holland and F. Z. Peng; "Control strategy for fuel cell vehicle traction drive systems using the Z-source inverter," in Proc of IEEE Vehicle Power and Propulsion Conference, Sept. 2005, pp. 639-944.

[7] F. Z. Peng, X. Yuan, X. Fang, and Z. Qian, "Z-source inverter for adjustable speed drives," IEEE Power Electronics Letters, June 2003, Vol. 1, No. 2, pp. 33-35

[8] Joel Anderson and F.Z. Peng, "Four Quasi-Z-Source Inverters," Power Electronics Specialists Conference 2008 PESC '08 39th IEEE 15-19, June 2008, pp. 2743-2749.

[9] Marco Liserre, Frede Blaabjerg, Steffan Hansen, "Design and control of an LCL-filter-based three-phase active rectifier," IEEE Transactions on Industry Applications, Vol. 4 No. 1, May. 2005, pp.1281 - 1291.

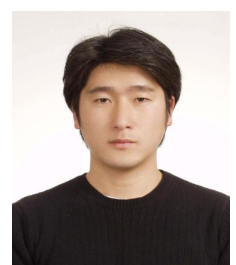

Jong-Hyoung Park was born in Korea in 1979. He received B.S. and M.S. degrees in Electrical Engineering from Yeungnam University and Kyungpook National University, Taegu, Korea in 2006 and 2008, respectively. $\mathrm{He}$ is currently working toward his Ph.D. at Kyungpook National University. His current research interest is in inverters for microgrid systems.

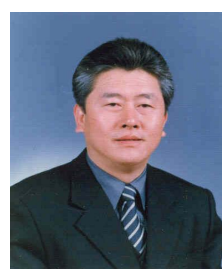

Heung-Geun Kim was born in Korea in 1956. He received his B.S., M.S. and Ph.D. in Electrical Engineering from Seoul National University in 1980, 1982 and 1988, respectively. Since 1984, he has been with the Department of Electrical Engineering at Kyungpook National University, where he is currently a Full Professor. He was with the department of Electrical Engineering at the University of Wisconsin-Madison, as a Visiting Scholar from 1990 to 1991. From 2006 to 2007, he also served as a Visiting Scholar with the Department of Electrical and Computer Engineering at Michigan State University, USA. His current research interests are in the control of ac machines and PV power generation.

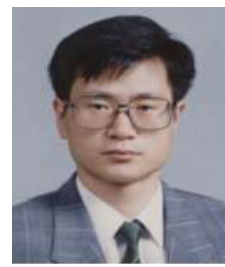

Eui-Cheol Nho received a B.S. in Electrical Engineering from Seoul National University, Seoul, Korea in 1984, and a M.S. and a Ph.D. in Electrical and Electronic Engineering form KAIST in 1986 and 1991, respectively. He was with Powertech Co., Ltd., Korea, as a Chief of the R\&D Center from 1991 to 1995. In 1995, he joined the Department of Electrical Engineering at Pukyong National University, Busan, Korea, where he is currently a Professor. From 1997 to 1998 , he served as a Visiting Scholar with the Department of Electrical and Computer Engineering at the University of Wisconsin-Madison, USA. From 2005 to 2006, he also served as a Visiting Scholar with the Department of Electrical Engineering and Computer Science at the University of California, Irvine, USA. His current research interests are in high voltage PWM converters, soft-switching converters, dynamic UPS, power line conditioners, etc.

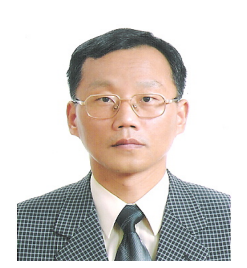

Tae-Won Chun was born in Korea in 1959. He received a B.S. degree in Electrical Engineering from Pusan National University in 1981, and his M.S. and Ph.D. in Electrical Engineering from Seoul National University in 1983 and 1987, respectively. Since 1986, he has been with the Department of Electrical Engineering at Ulsan University, where he is currently a Full Professor. He is also currently a Vice-President of the Korean Institute of Power Electronics (KIPE). His current research interests are in the control of electrical machines, power converter circuits and the control of linear compressors. 